\title{
Assisted dying in countries where it has been legalised and the recent debate in the UK
}

\author{
Ian Jack Donald Hamilton* \\ Institute of Health and Wellbeing, University of Glasgow, Glasgow, UK
}

\section{Letter}

The purpose of this letter is to clarify the terms assisted dying, assisted suicide and voluntary euthanasia, discuss the current legislation and the recent debate in the UK, outline the situation in countries where assisted dying has been legalised and consider the way forward.

\section{Assisted dying, assisted suicide and voluntary euthanasia}

- Assisted dying is the prescribing of life ending drugs to terminally ill, mentally competent adults (which they then selfadminister) [1].

- Assisted suicide is any act which intentionally helps another person to kill themselves by providing them with the means to do so (most commonly by prescribing lethal medication) [2].

- Voluntary euthanasia is an intervention by a doctor with the intention of ending a life in order to relieve suffering (usually by the administration of life ending drugs) [3].

\section{The current situation in the UK and the recent assisted dying} bill

Euthanasia in England and Wales is considered as manslaughter or murder, the suicide act of 1961 making it an offence to encourage or assist a suicide or a suicide attempt and anyone doing so would face up to 14 years in prison. In Northern Ireland the law is similar. In Scotland there is no specific law on assisted suicide but a prosecution would be considered under homicide legislation. The recent assisted dying bill in the UK parliament applied only to terminally ill patients in England and Wales.

The patient would have had to be an adult with less than six months to live, mentally competent, informed of the alternatives and have made the choice through their own free will. Two independent doctors would have had to agree that the patient had made an informed decision. A doctor would prescribe a lethal dose of drugs which the patient would administer themselves and each case would have been reviewed by a high court judge [4].

\section{The law in countries where assisted dying has been legalised}

- In the US states of Oregon, Vermont, Washington, Montana and California the patient has to be terminally ill.

- In the Netherlands the patient's suffering must be unbearable with no prospect of improvement. The suffering can include the loss of personal dignity and increasing personal deterioration and fear of suffocation.
- In Belgium the patient's suffering must be constant and unbearable and result from a serious and incurable disorder. The patient does not require to have a terminal illness but there are additional checks if the patient is not terminally ill.

- In Canada a patient must have a grievous and irremediable medical condition which causes enduring and intolerable suffering.

In all regimes, the patient must be competent and well-informed [5]

\section{Patients under the age of 18}

Euthanasia for patients under the age of 18 is only permitted in the Netherlands and Belgium. In the Netherlands a competent patient between the ages of 16 and 18 may request euthanasia or assisted suicide and the parent or guardian does not have a veto but they must be consulted. Competent patients aged between 12 and 16 may also qualify but only with the consent of their parent or guardian. In Belgium a competent patient under the age of 18 can request euthanasia with parental consent but additional scrutiny of the child's competence is required and suffering based on a psychiatric disorder has to be excluded [5].

\section{Validating a request to end a life}

In the Netherlands and Belgium a request to end a life has to be validated by a second doctor who must see the patient to confirm that their suffering is unbearable. In the five US states the second doctor must also confirm that the patient is terminally ill. In Oregon, Washington and Vermont the patient must be seen by a mental health professional if either the attending or consulting doctor suspects they are suffering from a psychological disorder causing impaired judgement. In Oregon the doctor must report each prescription and each death to the state health department and if the doctor has failed to comply with the legal requirements the case is referred to the doctor's regulating body. In the Netherlands each case must be reported to the coroner. The report is passed to a regional committee and if the committee finds the doctor has failed to follow the legal requirements the case is referred to the prosecution service and the doctor's regulating body. Belgium has a similar process [5].

Correspondence to: Ian Jack Donald Hamilton, Researcher, Institute of Health and Wellbeing, University of Glasgow, 1 Lilybank Gardens, Glasgow, G12 8RZ, UK, Tel: 01415605615; E-mail: ijdhamilton@doctors.org.uk

Key words: assisted dying, legal requirements, UK debate

Received: October 28, 2016; Accepted: November 22, 2016; Published: November 24, 2016 


\section{The way forward}

Supporters of assisted dying emphasize the relief of suffering, individual autonomy and the patient's right to be free from paternalistic state intrusion. They also suggest that allowing assisted dying under controlled and restricted conditions is preferable to acceding to secret and unregulated activity. Opponents however stress that it would represent a profound change in social values and have serious unintended consequences with any gains not being worth the risks involved [3].

The recent unsuccessful attempt to legalise assisted dying in the UK highlights the concern of most doctors that they would become social agents in the direct action to end life [6]. Perhaps if more attention was paid to the experience of dying patients and the views of their relatives and carers [7] doctors would be better equipped to provide optimal end of life care [8] and assisted dying would no longer be such a contentious issue.

\section{References}

1. White C, Dyer O, Rada AG (2015) Assisted dying law and practice around the world BMJ 351: h4481. [Crossref]

2. Materstvedt LJ, Clark D, Ellershaw J, Førde R, Gravgaard AM, et al. (2003) Euthanasia and physician-assisted suicide: a view from an EAPC Ethics Task Force. Palliat Med 17: 97-101. [Crossref]

3. Bachman JG, Alcser KH, Doukas DJ, Lichtenstein RL, Corning AD, et al. (1996) Attitudes of Michigan Physicians and the Public toward legalising Physician-Assisted Suicide and Voluntary Euthanasia. N Engl J Med 334: 303-309. [Crossref]

4. Lewis P (2015) Assisted dying: What does the law say in different countries? Source $\mathrm{BBC}$.

5. BBC (2015) Assisted dying debate: The key questions.

6. McEvoy P (2015) Euthanasia, ethics and the Gordian knot. Is the Hippocratic Code obsolete? Br J Gen Pract 65: 624-62. [Crossref]

7. Leadership Alliance for the Care of Dying People (2014) One chance to get it right: improving people's experience of care in the last few days and hours of life. London: Department of Health, 2014.

8. Hamilton IJ (2016) Euthanasia: providing optimal terminal care. Br J Gen Pract 66: DOI:3399/bjgp16X683605.

Copyright: @2016 Hamilton IJD. This is an open-access article distributed under the terms of the Creative Commons Attribution License, which permits unrestricted use, distribution, and reproduction in any medium, provided the original author and source are credited. 